\title{
Penerapan Model CTL (Contextual Teaching And Learning) Melalui Alat Peraga Torso dalam Peningkatan Hasil Belajar Pada Mata Pelajaran IPA Kelas V di SDN Muara Bumban 1 Kabupaten Murung Raya
}

\author{
Erisma Nurhaliza
}

Institut Agama Islam Negeri Palangka Raya, nurhalizaerisma@gmail.com

\begin{abstract}
ABSTRAK
Penelitian ini bertujuan untuk mengetahui: 1) Penerapan yang dilakukan dengan menggunakan model pembelajaran CTL (contextual taching and learning) dengan menggunakan alat peraga torso pada mata pelajaran IPA kelas V di SDN Muara Bumban 1 Kecamatan Murung Kabupaten Murung Raya. 2) Untuk mengetahui peningkatan hasil belajar siswa setelah menggunakan model CTL (Contextual Teaching and Learning) kelas V di SDN Muara Bumban 1 Kecamatan Murung Kabupaten Murung Raya. Penelitian ini menggunakan metode campuran dan kombinasi (mixed methodology). Populasi dan sampel data dalam penelitian ini sebanyak 15 orang siswa. Teknik pengumpulan data yang digunakan dalam penelitian ini adalah, observasi, tes objektif (pre-test dan posttest) dan dokumentasi. Instrument yang digunakan dalam mengumpulkan data yaitu dengan menggunakan soal pre-test dan post-test dan lembar observasi. Teknis analisis data yang digunakan dalam penelitian ini yaitu dengan menggunakan uji validitas dan normalitas. Hasil penelitian ini menunjukkan bahwa: 1) Penerapan yang dilakukan menggunakan model pembelajaran CTL (contextual taching and learning) dengan menggunakan alat peraga torso menunjukan bahwa total hasil akhir dari lembar pengamatan yaitu 52,6\% dengan kategori baik. 2) Adanya peningkatan setelah mendapat perlakuan (treatment) dengan rata-rata nilai pre-test 43,733 dan post-test yaitu sebesar 87,2 dan nilai $\mathrm{N}$-gain 0,767 dengan kriteria sedang.
\end{abstract}

Kata Kunci: CTL (Contextual Teaching and Learning), Hasil belajar siswa

\begin{abstract}
So that the formulation of this problem is 1) How is the application of the CTL (Contextual Teaching and Learning) model through the Torso Props Class V at SDN Muara Bumban 1, Murung District, Murung Raya District. 2) Is there an increase in student learning outcomes after the application of the fifth grade CTL (Contextual Teaching and Learning) model at SDN Muara Bumban 1, Murung District, Murung Raya Regency. This study aims to determine: 1) The application is carried out using the CTL (contextual taching and learning) learning model using torso props in the fifth grade natural science subjects at SDN Muara Bumban 1, Murung District, Murung Raya District. 2) To find out the increase in student learning outcomes after using the CTL (Contextual Teaching and Learning) model class V at SDN Muara Bumban 1, Murung District, Murung Raya Regency. This study uses a mixed methodology (mixed methodology). The
\end{abstract}


population and sample data in this study were 15 students. Data collection techniques used in this study were observation, objective tests (pre-test and post-test) and documentation. The results of this study indicate that: 1) The application is carried out using the CTL (contextual taching and learning) learning model using torso teaching aids that students tend to be active during learning and listening to what is explained and conveyed by the teacher. 2) There is an increase after is 43,733 receiving treatment (treatment) with an average post-test value that is equal to 87.2 and $\mathrm{N}$-gain value of 0.767 with moderate criteria.

Keywords: CTL (Contextual Teaching and Learning), student learning outcomes.

\section{Article history:}

Received: 28-11-2019

Revised: $10-12-2019$

Accepted: 14-1-2020

Copyright (c) 2020 Nurhaliza

\section{Pendahuluan}

Pendidikan pada dasarnya adalah suatu proses untuk membantu manusia dalam mengembangkan dirinya, sehingga mampu menghadapi segala perubahan dan permasalahan dengan sikap terbuka serta pendekatan-pendekatan yang kreatif tanpa harus kehilangan identitas dirinya. Sekolah merupakan bagian dari sistem pendidikan formal yang mempunyai aturan-aturan jelas. Guru adalah fasilitator yang berperan dalam keberhasilan siswa. Oleh karena itu, guru harus tepat dalam memilih model pembelajaran yang akan digunakan agar hasil belajarnya tercapai.

Menurut Permendikbud No. 103 Tahun 2014 pasal 2 ayat 2 tentang Pembelajaran pada Pendidikan Dasar dan Pendidikan Menengah menyatakan bahwa metode pembelajaran merupakan cara atau teknik yang digunakan oleh pendidik untuk menangani suatu kegiatan pembelajaran yang mencakup antara lain ceramah, tanya-jawab, dan diskusi. Menurut Sutikno (2009:76) metode pembelajaran adalah cara-cara menyajikan materi pelajaran yang dilakukan oleh pendidik agar terjadi proses pembelajaran pada diri peserta didik dalam upaya untuk mencapai tujuan.

Prastowo menyatakan (2013: 58-59) dalam proses belajar diperlukan suatu kondisi yang memungkinkan siswa dapat belajar dengan baik. Sebagai seorang pendidik, guru harus mampu menciptakan kondisi 
pembelajaran yang kondusif di kelas bagi siswa. Kreativitas seorang guru dalam memotivasi siswa harus benar-benar diasah dengan baik. Seorang guru yang baik tidak hanya mampu mentransfer ilmu pengetahuan tetapi juga mampu membangkitkan minat belajar siswanya. Hal ini berbeda dengan praktik pembelajaran lama yang cenderung berlangsung satu arah yaitu guru yang memberikan dan siswa yang menerima.

Ada beberapa model yang dapat diterapkan dalam pembelajaran salah satunya yaitu model pembelajaran contextual teaching and learning. Model pembelajaran contextual teaching and learning adalah suatu model belajar yang model pembelajran contextual teaching and learning. Dengan adanya model pembelajaran, seorang guru harus pandai memilih dan menentukan model pembelajaran yang tepat dan sesuai dengan materi yang diajarkan agar tujuan pembelajaran dapat tercapai dengan maksimal terutama dalam pembelajaran IPA yang membutuhkan model-model yang tepat.

IPA merupakan pelajaran wajib yang diikuti oleh peserta didik pada setiap jenjang pendidikan. Pada pembelajaran IPA, guru diharapkan dapat menyampaikan materi dengan baik. Bahkan guru diharapkan memotivasi siswa untuk meningkatkan prestasi pada mata pelajaran IPA. Guru seharusnya menggunakan model yang tepat dalam pembelajaran IPA agar peserta didik dapat belajar dengan baik dan menyenangkan dan peserta didik dapat mengoptimalkan kemampuannya sehingga prestasi pada pembelajaran IPA dapat ditingkatkan.

Model CTL akan menjadi sebuah solusi efektif apabila diterapkan dalam pembelajaran IPA dengan menggunakan model CTL diharapkan dapat memberikan solusi dan suasana baru yang menarik dalam pembelajaran IPA sehingga memberikan konsep baru dan dapat mengoptimalkan kemampuan peserta didik agar prestasi belajar IPA dapat meningkat. 
Istilah alat peraga dewasa ini disebut sebagai media pendidikan, ada pula yang menyebutnya sebagai Audio Visual Aids (AVA) atau alat bantu pandang dengar. Gagne dalam Nurbatni (2005) menyatakan bahwa media atau alat peraga adalah segala bentuk alat fisik yang dapat menyajikan pesan serta merangsang siswa untuk belajar.

Berdasarkan hasil pengamatan yang telah dilakukan di SDN Muara Bumban 1 Kecamatan Murung Kabupaten Murung Raya selama 14 hari, dinyatakan bahwa pembelajaran IPA masih rendah dilihat dari hasil belajar siswa, seperti kegiatan pembelajaran yang dilakukan hanya menulis dan mendengarkan. Selain itu dilihat juga bahwa proses pembelajaran masih menekankan pada metode ceramah, dikte dan tanya jawab, sedangkan pada pembelajaran IPA ada bagian-bagian yang menuntut untuk keaktifan siswa dalam menemukan konsep-konsep dari pengalaman atau praktik yang dilakukan. Proses pembelajaran yang seperti itu cenderung membuat siswa pasif yang pada akhirnya akan berpengaruh terhadap hasil belajar siswa.

Kondisi yang demikian juga terjadi pada siswa kelas V SDN Muara Bumban 1. Ketika pembelajaran IPA, metode yang digunakan guru adalah metode ceramah, dikte dan tanya jawab sehingga siswa hanya mencatat, memperhatikan mendengarkan dan menjawab. Metode demikian ternyata belum bisa membuat peserta didik menjadi aktif dan paham terhadap materi yang disampaikan karena ketika diberi soal masih ada sebagian siswa yang kesulitan dalam mengerjakannya. Hal ini tampak pada pencapaian nilai belajar siswa yang jika dilihat nilai dari rata-rata masih ada 7 sampai 8 siswa yang belum memenuhi KKM yang telah ditentukan yaitu 70 dengan pencapaian ketuntasan oleh siswa hanya di bawah 50\%. Rendahnya pencapaian nilai akhir siswa ini, menjadi indikasi bahwa pembelajaran yang dilakukan selama ini hasil belum maksimal.

\section{Metode}

Penelitian ini menggunakan metode campuran (Mixed Method), 
yaitu metode yang memadukan pendekatan kualitatif dan kuantitatif dalam hal metodologi (seperti dalam tahap pengumpulan data), dan kajian model campuran memadukan dua pendekatan dalam semua tahapan proses penelitian (Sugiyono, 2013:404). Mixed Method juga disebut sebagai sebuah metodologi yang memberikan asumsi filosofis dalam menunjukkan arah atau memberi petunjuk cara pengumpulan data dan menganalisis data serta perpaduan pendekatan kuantitatif dan kualitatif melalui beberapa fase proses penelitian. Strategi metode campuran yang digunakan dalam penelitian ini adalah urutan analisis kuantitatif dan kualitatif, tujuan strategi ini adalah untuk mengidentifikasikan komponen konsep (sub-konsep) melalui analisis data kuantitatif dan kemudian mengumpulkan data kualitatif guna memperluas informasi yang tersedia (Sugiyono, 2013:405).

Metode penelitian pada dasarnya merupakan cara ilmiah untuk mendapatkan data dengan tujuan dan kegunaan tertentu.
Jenis penelitian ini adalah penelitian campuran (mixed method) dengan menggunakan pendekatan pra-eksperimen dan menggunakan one group pre-test post-test design, dikatakan bahwa pendekatan pra-eksperimen merupakan jenis penelitian yang belum dilaksanakan dengan sungguh-sungguh. Maka dapat dikatakan terdapat variabel luar yang berpengaruh terhadap terbentuknya variabel dependen. Hal tersebut terjadi dikarenakan tidak ada variabel kontrol sehingga dapat mempengaruhi variabel dependen, dimana variabel dependen sendiri belum tentu dipengaruhi oleh variabel independen. Melalui desain ini akan diketahui efektivitas implementasi pendidikan karakter sebelum dan sesudah perlakuan. Oleh karena itu, peneliti memberikan kuesioner pre-test (tes awal) dan post-test (tes akhir).

Penelitian ini menggunakan pra-eksperimen design dengan menggunakan rancangan One Group Pretest-Posttest yaitu rancangan ini terdiri dari satu kelompok (tidak ada kelompok control). 
Penelitian ini dilakukan di Sekolah Dasar Negeri Muara bumban 1, yang beralamat di Jalan Raden Naun Gang Pelajar Kecamatan Murung Kabupaten Murung Raya, dengan alasan sekolah ini memiliki banyak alatalat peraga atau media pembelajaran akan tetapi tidak pernah digunakan sama sekali. Jadi peneliti ingin melihat bagaimana proses pembelajaran menggunakan metode Contextual Teaching and Learning dengan menggunakan alat peraga torso disekolah tersebut.

\section{Permasalahan}

Penelitian ini dilakukan di SDN Muara Bumban 1 Kecamatan Murung Kabupaten Murung Raya, pada tanggal 12 Agustus 2019 sampai dengan 21 Agustus 2019 dengan jumlah pertemuan sebanyak empat kali. Penelitian ini mengambil populasi seluruh siswa kelas V SDN Muara Bumban 1. Sedangkan sampel dalam penelitian ini adalah siswa kelas $\mathrm{V}$ dengan jumlah 15 siswa. Adapun fokus dalam penelitian ini ialah mengenai penerapan model pembelajaran CTL (contextual teaching and learning) terhadap hasil belajar IPA materi Rangka manusia dengan menggunakan alat peraga torso siswa kelas $\mathrm{V}$ SDN Muara Bumban 1, jadi terdapat dua pokok bahasan yang akan di bahas yaitu pengaruh penerapan model pembelajaran CTL (contextual teaching and learning) terhadap hasil belajar IPA dengan menggunakan alat peraga torso pada siswa kelas $\mathrm{V}$ di SDN Muara Bumban 1, dan besar pengaruh penerapan model pembelajaran CTL (contextual teaching and learning) terhadap hasil belajar IPA dengan menggunakan alat peraga torso pada siswa kelas V di SDN Muara Bumban 1.

Data dalam penelitian ini peneliti diperoleh melalui beberapa metode, yaitu 1) Metode observasi, metode ini bertujuan untuk memperoleh data yang diinginkan peneliti untuk mengamati secara langsung kondisi sekolah terutama kelas yang akan digunakan dalam penelitian serta proses pembelajaran matematika. 2) metode dokumentasi, dimana peneliti memperoleh data 
langsung mengenai keadaan guru dan siswa pada sekolah tempat penelitian, data nilai yang dibutuhkan oleh peneliti, serta foto-foto pendukung dalam dalam penelitian. 3) Metode tes, metode tes digunakan peneliti untuk mengetahui hasil belajar siswa pada pokok bahasan rangka manusia di SDN MUara Bumban 1 Kecamatan Murung Kabupaten Murung Raya.

\section{Penerapan model CTL (contextual teaching and} learning) melalui alat peraga torso kelas V di SDN Muara Bumban 1 Kecamatan Murung Kabupaten Murung Raya.

Penerapan pembelajaran IPA dengan menggunakan model pembelajaran $\mathrm{CTl}$ (contextual teaching and learning) dengan menggunakan alat peraga torso dalam pelajaran IPA dinilai dengan menggunakan instrumen yaitu lembar pengamatan aktivitas guru. Lembar pengamatan yang digunakan telah dikonsultasikan dan divalidasi oleh dosen ahli sebelum dipakai untuk mengambil data penelitian.

Pengamatan aktivitas guru dengan penerapan model CTL dngan menggunakan alat peraga torso dalam mata pelajaran IPA dilakukan selama pembelajaran berlangsung.

Sebelum pembelajaran dimulai, pengamat diberikan penjelasan cara pengisian pengelolaan pembelajaran untuk menyamakan pendapat tentang aspek yang diamati. Pengamatan ini dilakukan oleh dua orang pengamat yang terdiri dari seorang guru SDN Muara Bumban 1 dan seorang mahasiswa UIN Banjarmasin Program Studi PGMI yang sudah diberikan penjelasan cara untuk mengisi lembar pengamatan pengelolaan secara benar. Berdasarkan instrumen penelitian yang dilakukan oleh peneliti di lapangan serta penerapan metode yang terdiri dari pertemuan ke-1 sampai pertemuan ke-4, ada beberapa hasil penelitian yang diperoleh diantaranya sebagai berikut: 
Tabel 1 Hasil Pengamat Aktivitas Guru

No

\section{Deskriptor}

Aktivitas Guru

Indikator

1 Menyampaikan

a. Memotivasi dan membangkitkan minat

Pengamat Pengamat

tujuan

belajar siswa

b. Menyampaikan apersepsi $\quad 5$

c. Menghubungan materi yang akan 4

disampaikan dengan materi sebelumnya (asosiasi)

d. Menyampaikan kompetensi dasar $\quad 5$

e. Menyampaikan tujuan pembelajaran

$5 \quad 5$

\begin{tabular}{|c|c|c|c|c|c|}
\hline \multirow[t]{3}{*}{2} & \multirow[t]{3}{*}{$\begin{array}{l}\text { Menyampaikan } \\
\text { Materi }\end{array}$} & & $\begin{array}{l}\text { Menanyakan fungsi rangka yang ada pada } \\
\text { manusia(Konstruktivisme) }\end{array}$ & 4 & 5 \\
\hline & & b. & $\begin{array}{l}\text { Membimbing siswa membuktikan konsep } \\
\text { IPA melalui pengalaman langsung (Inquiry) }\end{array}$ & 4 & 4 \\
\hline & & c. & $\begin{array}{l}\text { Memberikan kesempatan pada siswa untuk } \\
\text { mengidentifikasikan rangka manusia } \\
\text { (Inquiry) }\end{array}$ & 5 & 4 \\
\hline \multirow[t]{6}{*}{3} & \multirow{6}{*}{$\begin{array}{l}\text { Membangkitkan } \\
\text { pengetahuan } \\
\text { siswa }\end{array}$} & a. & $\begin{array}{l}\text { Melibakan siswa secara langsung dalam } \\
\text { mecari informasi tentang rangka mansia }\end{array}$ & 5 & 5 \\
\hline & & b. & $\begin{array}{l}\text { Menjelaskan rangka manusia dengan } \\
\text { menggunakan alat peraga torso ( Inquiry) }\end{array}$ & 4 & 5 \\
\hline & & c. & $\begin{array}{l}\text { Membantu siswa agar menguasai materi } \\
\text { pelajaran }\end{array}$ & 5 & 4 \\
\hline & & d. & $\begin{array}{l}\text { Mengajukan pertanyaan kepada siswa } \\
\text { (Questioning) }\end{array}$ & 4 & 5 \\
\hline & & e. & $\begin{array}{l}\text { Memberikan kesempatan berfikir kepada } \\
\text { siswa untuk menjawab pertanyaan } \\
\text { (Inquiry) }\end{array}$ & 4 & 4 \\
\hline & & f. & $\begin{array}{l}\text { Memberi kesempatan kepada siswa untuk } \\
\text { bertanya (Questioning) }\end{array}$ & 4 & 4 \\
\hline \multirow[t]{2}{*}{4} & \multirow[t]{2}{*}{$\begin{array}{l}\text { Membentuk } \\
\text { kelompok }\end{array}$} & a. & $\begin{array}{l}\text { Menjelaskan pembagian kelompok kecil } \\
\text { dan membagikan siswa menjadi beberapa } \\
\text { kelompok (Learning community) }\end{array}$ & 5 & 5 \\
\hline & & b. & $\begin{array}{l}\text { Mendampingi siswa saat berdiskusi dengan } \\
\text { kelompok (Modeling) }\end{array}$ & 5 & 5 \\
\hline
\end{tabular}




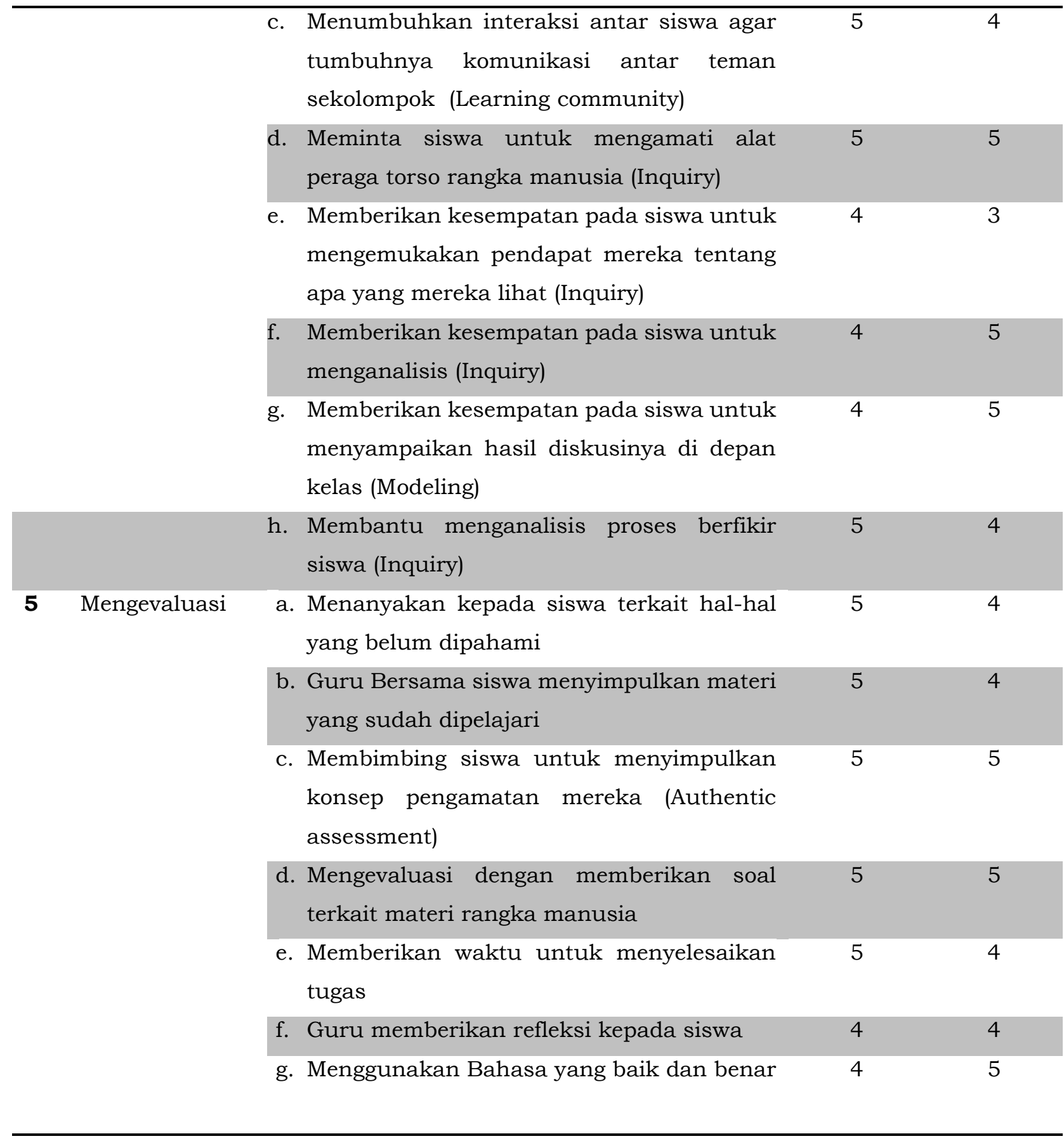

Analisis hasil lembar observasi :

Nilai $=(1 \times 30)+(4 \times 25)+(5 \times$ $32) / 5 \times 100 \%=(3+100+160) 5 \times$ $100 \%$

$$
\begin{gathered}
=236 / 5 \times 100 \% \\
52,6 \%
\end{gathered}
$$

Dapat dilihat dari hasil analsisi lembar observasi yang dilihat oleh 2 pengamat yaitu dengan nilai $52,6 \%$ dengan kategori baik. Jadi, dapat dikatakan bahwa guru mampu menerapkan model pembelajaran CTL (contextual teaching and lerning) melalui alat peraga torso 
pada mata pelajaran IPA dengan baik.

Hasil analisis observasi terhadap kegiatan guru merupakan suatu gambaran keterampilan guru dalam melakukan kegiatan pembelajaran dengan menggunakan model pembelajaran CTL (contextual teaching and leraning). Observasi dilakukan oleh seorang pengamat yaitu observer dan kepala sekolah dengan menggunakan lembar observasi guru yang ada pada lampiran. Hasil observasi aktivitas guru yang memperoleh skor cukup dan masih perl diperbaiki yaitu guru kurang memberikan kesempatan pada siswa pendapatnya, itu dilakukan akan tetapi tidak dilakukan dengan maksimal.

Observasi terhadap aktivitas guru dalam proses pembelajaran dengan menggunakan model pembelajaran CTL (contextual teching and learning) dengan menggunakan alat peraga torso pada mata pelajaran IPA materi rangka manusia yang dilakukan oleh seorang observer. Adapun aspek yang diamati oleh observer yaitu dilihat pada kriteria penilaian terhadap aktivitas guru yaitu memperoleh skor nilai 4 (baik) dan 5 (sangat baik). Hasil observasi terhadap aktivitas guru yang dilakukan oleh observer termasuk dalam kategori baik dan semua aspek-aspek yang terdapat dalam lembar observasi sudah berjalan dengan baik dalam proses pembelajaran dengan penerapan model CTL (contextual teaching and lerning) dengan menggunakan alat peraga torso pada mata pelajaran IPA materi rangka manusia.

Hasil analisis data menggunakan lembar observasi terhadap aktivitas guru pada saat proses pembelajaran dengan menggunakan model pembelajaran CTL (contextual teching and learning) dengan menggunakan alat peraga torso pada mata pelajaran IPA materi rangka manusia ternyata dapat menjadi lebih baik dan hasil belajar siswa juga mengalami peningkatan setelah diberikannya perlakuan. Hal ini ditunjukkan dengan adanya peningkatan hasil belajar siswa pada saat melakukan proses 
pembelajaran dengan nyatakan valid dan 28 butir menggunakan model pembelajaran CTL (contextual teching and learning) dengan menggunakan alat peraga torso pada mata pelajaran IPA materi rangka manusia. Selain itu siswa juga lebih aktif pada saat pembelajaran terlebih pada saat siswa belajar dengan berkelompok (masyarakat belajar) dan menyajikan hasil belajarnya di depan kelas.

1. Peningkatan hasil belajar siswa setelah penerapan model CTL (contextual teaching and learning) melalui alat peraga torso kelas $\mathrm{V}$ di SDN Muara Bumban 1 Kecamatan Murung Kabupaten Murung Raya.

a. Uji Validitas

Uji validitas digunakan menguji apakah soal pretest dan posttest terseut valid atau tiak digunakan untuk mengetahui hasil belajar. Hasil analisis validasi 60 butir soal dengan bantuan Microsoft Exel didapatkan 32 butir soal di soal dinyatakan tidak valid.

\section{Tabel 2 Keputusan Validitas}

Pretest dan Postest Hasil Belajar

$\begin{array}{cccc}\text { Item } & \mathbf{r} \text { hitung } & \mathbf{r} \text { tabel } & \begin{array}{c}\text { Keputusan } \\ \text { Valid }\end{array} \\ \text { 2. } & 0.530 & 0.514 & \text { Valid } \\ \text { 3. } & 0.451 & 0.514 & \text { Tidak Valid } \\ \text { 4. } & -0.733 & 0.514 & \text { Tidak Valid } \\ 5 . & 0.612 & 0.514 & \text { Valid } \\ 6 . & 0.682 & 0.514 & \text { Valid }\end{array}$

$\begin{array}{llll}\text { 7. } & -0.274 & 0.514 & \text { Tidak Valid }\end{array}$

8. $-0.107 \quad 0.514 \quad$ Tidak Valid

9. $-0.314 \quad 0.514 \quad$ Tidak Valid

10. $-0.234 \quad 0.514 \quad$ Tidak Valid

$\begin{array}{llll}\text { 11. } & 0.688 & 0.514 & \text { Valid }\end{array}$

12. $0.586 \quad 0.514 \quad$ Valid

13. $0.661 \quad 0.514 \quad$ Valid

14. $0.595 \quad 0.514 \quad$ Valid

15. $0.043 \quad 0.514 \quad$ Tidak Valid

16. $0.658 \quad 0.514 \quad$ Valid

17. $0.586 \quad 0.514 \quad$ Valid

18. $0.636 \quad 0.514 \quad$ Valid

19. $-0,358 \quad 0.514 \quad$ Tidak Valid

20. $-0.253 \quad 0.514 \quad$ Tidak Valid

21. $0.217 \quad 0.514 \quad$ Tidak Valid

$\begin{array}{llll}\text { 22. } & 0.612 & 0.514 & \text { Valid }\end{array}$

23. $0.557 \quad 0.514 \quad$ Valid

24. $0.064 \quad 0.514 \quad$ Tidak Valid

25. $0,703 \quad 0.514 \quad$ Valid

26. $0.636 \quad 0.514 \quad$ Valid

27. $0.128 \quad 0.514 \quad$ Tidak Valid 


\begin{tabular}{|c|c|c|c|c|}
\hline 28. & -0.074 & 0.514 & Tidak Valid & Berdasarkan tabel \\
\hline 29. & 0.835 & 0.514 & Valid & diketahui bahwa uji validitas yang \\
\hline 30. & -0.014 & 0.514 & Tidak Valid & dilakukan dengan \\
\hline 31. & 0.066 & 0.514 & Tidak Valid & responden 15 orang dan 60 item \\
\hline 32. & 0.044 & 0.514 & Tidak Valid & pernyataan, maka dinyatakan 32 \\
\hline 33. & 0.682 & 0.514 & Valid & item pernyataan valid hal tersebut \\
\hline 34. & 0.636 & 0.514 & Valid & dapat dilihat dari nilai $r$ hitung lebih \\
\hline 35. & 0.615 & 0.514 & Valid & besar dari nilai $r$ tabel yaitu 0,541 , \\
\hline 36. & 0.636 & 0.514 & Valid & dan 28 item pernyataan tidak valid \\
\hline 37. & 0.661 & 0.514 & Valid & hal tersebut dapat dilihat dari nilai \\
\hline 38. & 0.731 & 0.514 & Valid & $r$ hitung lebih kecil dari nilai $r$ tabel \\
\hline 39. & 0.806 & 0.514 & Valid & yaitu 0,541 \\
\hline 40. & 0.601 & 0.514 & Valid & Berdasarkan perhitungan \\
\hline 41. & 0.387 & 0.514 & Tidak Valid & atas tersebut menunjukkan indeks \\
\hline 42. & 0.543 & 0.514 & Valid & validitas yang dicari. Sehingga \\
\hline 43. & 0.124 & 0.514 & Tidak Valid & dapat digunakan sebagai \\
\hline 44. & 0.190 & 0.514 & Tidak Valid & instrumen dalam penelitian. \\
\hline 45. & 0.248 & 0.514 & Tidak Valid & Peneliti untuk memastikan \\
\hline 46. & 0.172 & 0.514 & Tidak Valid & kelayakan soal tersebut peneliti \\
\hline 47. & 0.395 & 0.514 & Tidak Valid & juga menggunakan validasi ahli \\
\hline 48. & 0,278 & 0.514 & Tidak Valid & yaitu 2 Dosen IAIN Palangka Raya \\
\hline 49. & 0.015 & 0.514 & Tidak Valid & yaitu: \\
\hline 50. & 0.731 & 0.514 & Valid & 1. Sulistyowati, M.Pd.I \\
\hline 51. & 0.567 & 0.514 & Valid & \\
\hline 52. & 0.578 & 0.514 & Valid & sebagai validator \\
\hline 53. & 0.703 & 0.514 & Valid & instrumen \\
\hline 54. & -0.073 & 0.514 & Tidak Valid & observasi. \\
\hline 55. & 0.198 & 0.514 & Tidak Valid & \\
\hline 56. & 0.602 & 0.514 & Valid & 2. Nanik \\
\hline 57. & 0.498 & 0.514 & Tidak Valid & Ningsih, \\
\hline 58. & 0.542 & 0.514 & Valid & \\
\hline 59. & -0.124 & 0.514 & Tidak Valid & sebaga1 \\
\hline 60. & -0.425 & 0.514 & Tidak Valid & instrumen penelitian \\
\hline
\end{tabular}


b. Uji Reliabilitas

Uji reliabilitas digunakan untuk mengetahui apakah item soal tersebut reliabel secara konsisten memberikan hasil ukur yang sama.

Berdasarkan perhitungan uji reliabilitas sebagaimana terlampir, maka semua item soal dinyatakan reliabel.

Dengan syarat jika $r \geq 0,70$ maka reliabilitasnya tinggi.

Tabel 3 Hasil Uji Reliabelitas SPSS

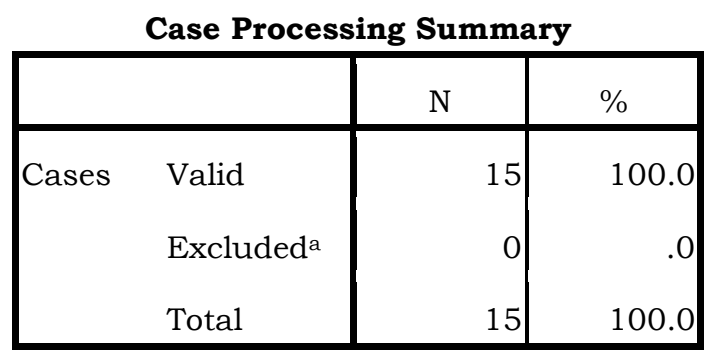

a. Listwise deletion based on all variables in the procedure.

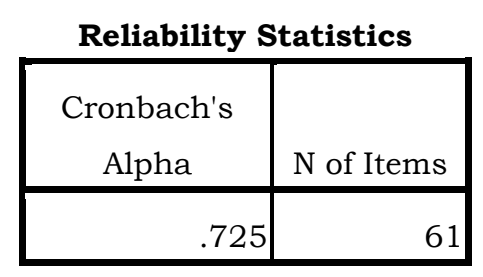

Berdasarkan hasil uji reliabilitas spss dapat dilihat pada kolom Cronbach's alpha > 0,05 maka data bisa dikatakan reliable. Pada uji spss diatas menunjukan signifikan 0,725 yang berarti $>0,05$ sehingga data reliable. Sehingga dapat digunakan sebagai instrument dalam penelitian. Syarat validitas dan reliabelitas sudah terpenuhi.

\section{Analisis Deskriptif}

Dari hasil pengukuran tes tertulis yang dilakukan terhadap 15 siswa kelas V di SDN Muara Bumban 1 berdasarkan nilai yang telah diperoleh maka melalui perhitungan dapat diperoleh persentase nilai pretest dan posttest sebagai berikut :

Tabel 4 Distribusi Frekuensi Berdasarkan Hasil Postest 


\begin{tabular}{|c|c|c|c|c|c|}
\hline \multicolumn{6}{|c|}{ HASIL POSTEST } \\
\hline & & Frequency & Percent & Valid Percent & $\begin{array}{c}\text { Cumulative } \\
\text { Percent }\end{array}$ \\
\hline \multirow[t]{7}{*}{ Valid } & 76 & 1 & 6.7 & 6.7 & 6.7 \\
\hline & 80 & 1 & 6.7 & 6.7 & 13.3 \\
\hline & 84 & 5 & 33.3 & 33.3 & 46.7 \\
\hline & 88 & 3 & 20.0 & 20.0 & 66.7 \\
\hline & 92 & 3 & 20.0 & 20.0 & 86.7 \\
\hline & 96 & 2 & 13.3 & 13.3 & 100.0 \\
\hline & Total & 15 & 100.0 & 100.0 & \\
\hline
\end{tabular}

Gambar 1 Histogram Distribusi Frekuensi Hasil Belajar Siswa

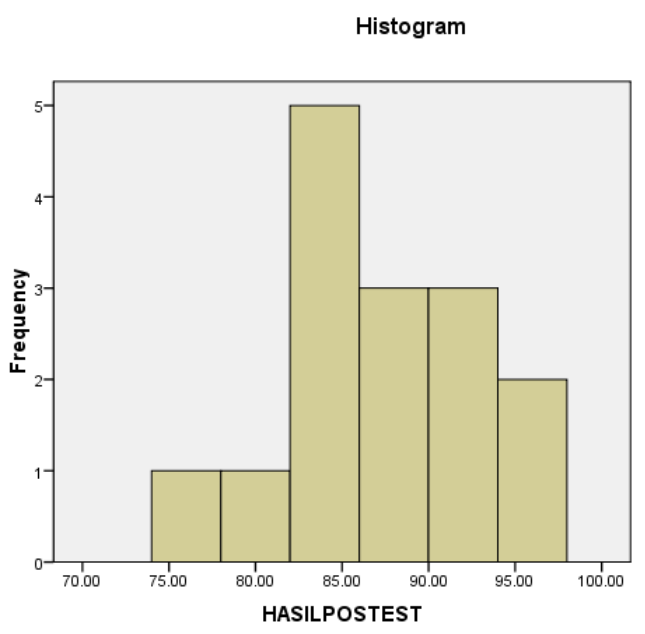

Data skor pretes dan postes yang diperoleh pada kelas $\mathrm{V}$ berdasarkan nilai ketuntasan individual yang ditetapkan oleh sekolah. Berikut tabel 4.5 yang berisi nilai pretes dan postes peserta kelas eksperimen.

Tabel 5 Nilai Pretes dan Postes

\begin{tabular}{|c|c|c|c|}
\hline \multirow{2}{*}{ No. } & Kelas V & \multicolumn{2}{|c|}{ Nilai } \\
\cline { 2 - 4 } & Kode & Pretes & Postes \\
\hline 1 & YAD & 40 & 80 \\
\hline 2 & ADT & 48 & 88 \\
\hline
\end{tabular}

\begin{tabular}{|c|l|c|c|}
\hline 3 & LAI & 40 & 84 \\
\hline 4 & RAS & 44 & 84 \\
\hline 5 & AFD & 60 & 92 \\
\hline 6 & LUP & 52 & 88 \\
\hline 7 & AND & 20 & 88 \\
\hline 8 & GIV & 32 & 92 \\
\hline 9 & NIL & 48 & 92 \\
\hline 10 & ARY & 28 & 84 \\
\hline 11 & AND & 40 & 84 \\
\hline 12 & LITAM & 68 & 96 \\
\hline 13 & NSR & 40 & 96 \\
\hline 14 & WAF & 64 & 84 \\
\hline 15 & NAB & 32 & 76 \\
\hline
\end{tabular}

Tabel 5 menunjukkan

bahwa perubahan nilai dari pretes

ke postes. Selanjutnya nilai yang

diperoleh tersebut dianalisis untuk mencari rata-rata hasil belajar dan $N$-gain yang secara singkat ada pada tabel 4.6 di bawah ini.

Tabel 6 Rata-rata Hasil Belajar Peserta

Didik

\begin{tabular}{|c|c|c|c|c|}
\hline Kelas & Prete & Poste & $\boldsymbol{N}$ - & Interpreta \\
& s & s & gain & si $\boldsymbol{N}$-gain \\
\hline Eksperi & 43.73 & 87.2 & & Tinggi \\
men & 3 & & 0,76 & \\
& & & 7 & \\
\hline
\end{tabular}


Data tabel 4.6 di atas menunjukkan bahwa nilai ratarata pretes hasil belajar peserta didik sebelum dilaksanakan pembelajaran oleh peneliti pada kelas eksperimen adalah 43.733 . Selanjutnya terjadi peningkatan ratarata pada postes dengan ratarata 87.2. Untuk nilai $N$-gain pada kelas eksperimen menunjukkan katagori sedang dengan nilai 0,767 .

Perbandingan rata-rata data pretes, postes,dan $N$-gain hasil belajar peserta didik pada kelas eksperimen ditampilkan pada gambar histogram 2, sedangkan rekapitulasi skor peserta didik, nilai hasil belajar pretes, postes dan $N$-gain secara lengkap dapat dilihat pada gambar dibawah ini :

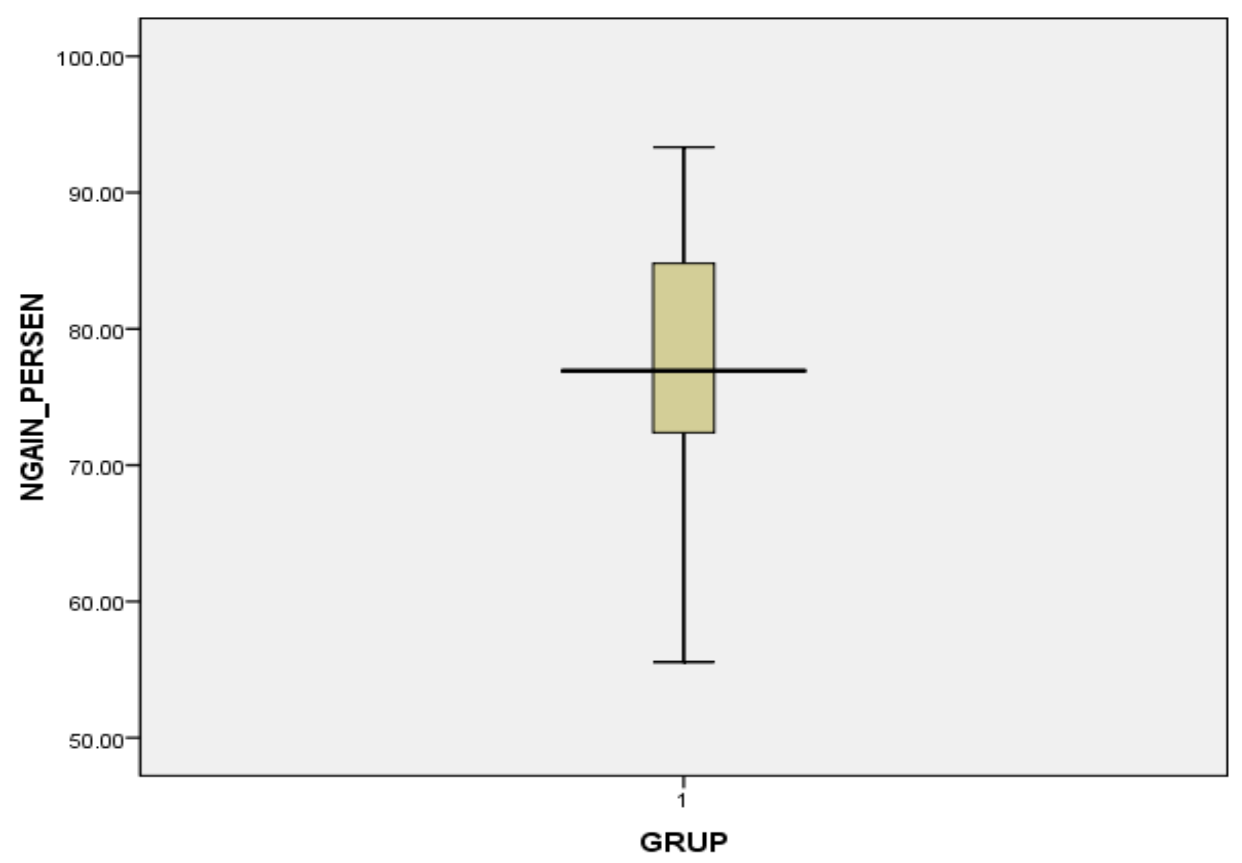

Gambar 2 Perbandingan hasil pretes dan postes kelas eksperimen
Uji Normalitas

Uji normalitas bertujuan untuk menguji apakah model 
regresi, variable terikat, variable bebas atau keduanya mempunyai distribusi normal atau tidak. Pengujian normalitas penelitian ini digunakan dengan menggunakan grafik P-P Plot yang tampak pada gambar 4.1 sebagai berikut :

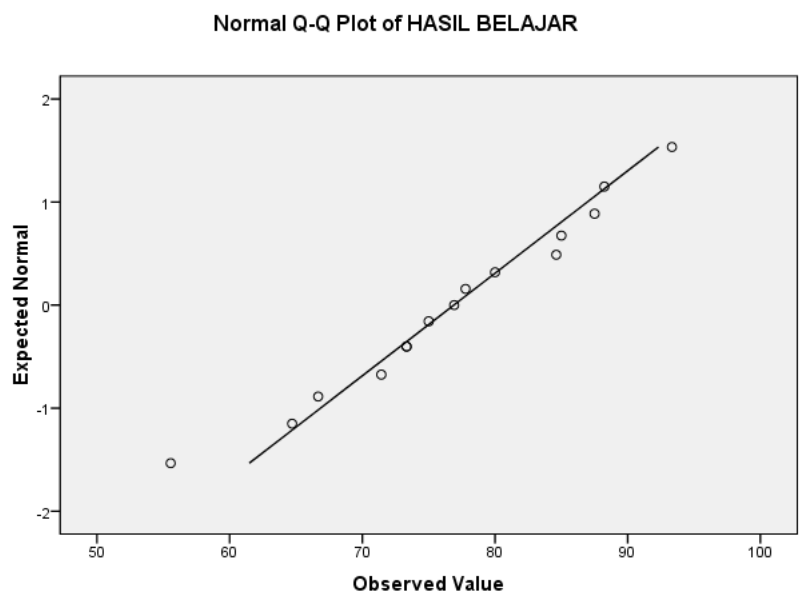

Gambar 3 Hasil Uji Normalitas

$$
\text { Pada gambar } 4.1
$$

menunjukan bahwa data menyebar disekitar garis diagonal dan mengikuti arah garis diagonal, maka dapat disimpulkan model regresi memenuhi asumsi normalitas.

\section{Uji Hipotesis Penelitian}

Untuk menguji hipotesis dalam penelitian ini digunakan rumus T-test. Paired T-test digunakan bila variabel yang dianalisis terdiri dari satu variabel terikat dan satu variabel bebas.

Tabel 7 data output $t$-tese

Paired Samples Test

\begin{tabular}{|c|c|c|c|c|c|c|c|c|}
\hline & \multicolumn{5}{|c|}{ Paired Differences } & \multirow[b]{3}{*}{$t$} & \multirow[b]{3}{*}{ df } & \multirow[b]{3}{*}{ Sig. (2-tailed) } \\
\hline & \multirow[b]{2}{*}{ Mean } & \multirow[b]{2}{*}{ Std. Deviation } & \multirow{2}{*}{$\begin{array}{l}\text { Std. Error } \\
\text { Mean } \\
\end{array}$} & \multicolumn{2}{|c|}{$\begin{array}{l}95 \% \text { Confidence Interval of the } \\
\text { Difference }\end{array}$} & & & \\
\hline & & & & Lower & Upper & & & \\
\hline Pair 1 pretest-postest & -43.467 & 12.546 & 3.239 & -50.415 & -36.519 & -13.418 & 14 & .000 \\
\hline
\end{tabular}


Berdasarkan perhitungan table spss di atas dapat di ketahui nilai sign(1-tailed) pada hasil belajar siswa adalah $0,000<0,05$, karena menggunakan sign (1-tailed) maka nilai signifikansinya harus dibagi menjadi 0,000/2 maka hasilnya 0,000 maka Ho diterima dan $\mathrm{Ha}$ ditolak. Jadi kesimpulannya ada peningkatan hasil belajar siswa antara postes dan pretest yang diberi perlakuan dengan menggunakan model CTL dalam pelajaran IPA dengan menggunakan alat peraga torso di kelas V.

Proses pembelajaran pada kelas $\mathrm{V}$ yang menerapkan model pembelajaran CTL (Contextual teaching and lerning) menunjukkan adanya peningkatan hasil belajar. Rata-rata nilai pretes kelas adalah 43.733 Sedangkan nilai postesnya adalah 87.2. Adapun selisih antara pretes dan postes pada kelas V yaitu sebesar 0,767 .

Peningkatan hasil belajar peserta didik pada kelas $\mathrm{V}$ juga terlihat pada nilai $N$-gain kelas $\mathrm{V}$ yaitu 0,767 dengan kriteria $N$-gain termasuk katagori tinggi.

Sebelum dilakukan pengujian hipotesis, data-data yang di dapat dari hasil belajar siswa baik pretes maupun postes dilakukan uji normalitas dan uji homogenitas. Uji normalitas dilakukan untuk mengetahui apakah sampel yang diteliti berdistribusi normal atau tidak. Sedangkan uji homogenitas dilakukan untuk menyelidiki apakah kedua sampel mempunyai varians yang sama atau tidak, apabila kedua kelas homogen maka data berasal dari populasi yang sama.

Berdasarkan hasil uji normalitas dan homogenitas dari hasil pretes 
dan postes ke dua kelas di dapat hasil yang menujukkan sampel yang diteliti dalam penelitian ini berdistribusi normal dan homogen.

Hasil analisis uji hipotesis penelitian menunjukkan bahwa model CTL (Contextual Teaching and Learing) memberikan pengaruh positif terhadap hasil belajar peserta didik yang mendapatkan peningkatan pada hasil belajar siswa.

Analisis data hasil penelitian menunjukkan bahwa terdapat peningkatan hasil belajar siswa dengan menggunakan model CTL (Contextual Teaching and Learing) dengan menggunakan alat peraga torso baik dilihat dari nilai postes, gain dan $\mathrm{N}$-gain untuk materi rangka manusia di kelas V SDN Muara Bumban 1 Kecamatan Murung Kabupaten Murung Raya.
Hal ini membuktikan bahwa dalam penelitian ini pembelajaran dengan model CTL (Contextual Teaching and Learing) dengan menggunakan alat peraga mempunyai pengaruh positif terhadap meningkatnya hasil belajar peserta didik. Hal itu dikarenakan proses pembelajaran pada model kooperatif telah mampu mengaktifkan peserta didik sehingga pembelajaran tidak lagi bersifat teacher center tapi telah bernuansa student center.

\section{Kesimpulan}

Berdasarkan hasil penelitian dan pembahasan yang telah dilakukan oleh peneliti dapat ditarik kesimpulan yaitu

1. Penerapan model pembelajaran Contextual Teaching Learning (CTL) dengan menggunakan alat peraga torso pada mata pelajaran materi rangka manusia kelas 5 
menunjukan bahwa total hasil akhir dari lembar pengamatan yaitu $52,6 \%$ dengan kategori baik.. Jadi, dapat dikatakan bahwa guru mampu menerapkan model pembelajaran CTL (contextual teaching and lerning) melalui alat peraga torso pada mata pelajaran IPA dengan baik.

2. Terdapatnya peningkatan hasil belajar siswa pada ranah kognitif. Pada nilai rata-rata pretest 43,733, setelah diberikan perlakuan, yaitu memberi kesempatan siswa menceritakan pengalamannnya yang berkaitan dengan materi (konstruktivisme), memberi giliran kepada setiap siswa untuk bertanya (bertanya), melakukan pembagian tugas pada setiap kelompok (masyarakat belajar), memberi petunjuk praktikum lebih jelas (pemodelan), memberi motivasi pada siswa yang pasif dalam diskusi sehingga siswa dapat.

3. aktif berdiskusi dan dapat menemukan konsep IPA dengan benar (inkuiri), dan membimbing siswa menyimpulkan hasil kegiatan dengan memberi pertanyaan pancingan (refleksi), terjadi peningkatan hasil belajar siswa menjadi 87,2 . Hal ini telah melampaui kriteria keberhasilan yang ditentukan dalam penelitian ini yaitu $75 \%$ siswa yang mendapat nilai minimal 75 .

\section{DAFTAR PUSTAKA}

Asnawir, H. \& Usman Basyiruddin M. 2002. Media Pembelajaran. Jakarta: Ciputat Pers. 
BSNP. 2006. Panduan Penyusunan

Kurikulum Tingkat Satuan

Pendidikan Jenjang Pendidikan

Dasar dan Menengah. Jakarta: BSNP Bungin, Burhan.2008. Penelitian Kualitatif Komunikasi, Ekonomi, Kebijakan Publik, dan Ilmu Sosial Lainnya. Jakarta: PT Kencana Prenada Media Group.

Dewi, Putu. 2014. Penerapan

Pendekatan Contextual teaching and Learning (CTL) Untuk Meningkatkan Keaktifan Hasil Belajar IPA siswa Kelas VI SDN 3 Tonja Tahun Ajaran 2014/2015.

Djamarah, Bahri, Syaiful. Zain, Aswan.

2005. Strategi Belajar Mengajar.

Rineka Cipta. Jakarta.

Elina, Anita. 2014. Penerapan Metode

Diskusi Melalui Media Torso

Terhadap Keaktifan Dan Hasil

Belajar Biologi Pada Siswa Kelas XI IPA SMA Negeri 2 Sorong.

Hidayati, Yulia, Maftuhah. 2012.

Pembelajaran Penjumlahan Bilangan

Pecahan dengan Metode CTL

(Contextual Teaching and Learning)di

SD Muhammadiyah. Surakarta.

Ibrahim. 2015. Metodelogi Penelitian

Kualitatif. Bandung : Alfabeta
Indahwati, $\quad$ Vista. 2017. Memberdayakan Berfikir Kritis Siswa Melalui Model Pembelajaran CTL (Contextual Teaching and Learning) dengan media Torso Ditinjau dari Gaya Kognitif Reflektif dan Impulsif. Tuban.

Irmansyah, Fiki, Bagus. 2014. Efektivitas Media Pembelajaran Model Torso Terhadap Hasil Belajar Biologi Siswa Kelas VIII SMP Negeri 1 Kalasan. Yogyakarta

Juliandri, Dedy. 2016. Penerapaan Pendekatan Contextual Teaching and Learning (CTL) Untuk Meningkatkan Hasil Belajar Statistika.

Majid Abdul. 2014. Pembelajaran Tematik Terpadu. Bandung: PT Remaja Rosdakarya.

Nurdin Syafrudin, Adriantoni. 2016.

Kurikulum dan Pembelajaran. Depok: PT Rajagrafindo Persada.

Prastowo Andi. 2013. Pengembangan

Bahan Ajar Tematik. Jogjakarta: DIVA Perss.

Pratiwi, Dian. 2013. Pemanfaatan Media Torso Untuk Meningkatkan Aktivitas dan Hasil Belajar IPA Siswa Kelas V SD No.2 Paket Agung Singaraja. Bali. 
Ristanti, Devi, dwi. 2015. Penerapan Model CTL (Contextual Teaching and Learning) Dengan Media Konkret Peningkatan Kreatifitas dan hasil Belajar Siswa Materi Relief Kelas IV SD Negeri 2 Sidomoro. Gersik.

Sanjaya, Wina. 2012. Media Komunikasi Pembelajaran. Jakarta: PT Kencana Prenada Media Group.

Sudjana, Nana. 2001. Media

Pengajaran (Penggunaan dan Pembuatannya). Bandung :Sinar Baru Algensindo.

Sugiyono. 2013. Metode Penelitian Kuantitatif, kualitatif dan $R \& D$. Bandung: ALFABETA,CV.

Susanto, Ahmad. 2013. Teori Belajar \& Pembelajaran di Sekolah Dasar. Jakarta: PT Kencana Prenada Media Group.

Trianto. 2010. Model pembelajaran Terpadu konsep, strategi, dan implementasinya dalam kurikulum tingkat satuan Pendidikan (KTSP). Jakarta: Bumi Aksara 